\title{
Efeitos de Dessecantes no Controle de Plantas Daninhas na Cultura Da SOJA ${ }^{1}$
}

\author{
Effects of Burndown Herbicides in Weed Control in Soybean Crop \\ PROCÓPIO, S.O. ${ }^{2}$, PIRES, F.R. ${ }^{2}$, MENEZES, C.C.E. ${ }^{3}$, BARROSO, A.L.L. ${ }^{2}$, MORAES, R.V. ${ }^{4}$, \\ SILVA, M.V.V. ${ }^{4}$, QUEIROZ, R.G. ${ }^{4}$ e CARMO, M.L. ${ }^{5}$
}

\begin{abstract}
RESUMO - Este trabalho teve como obj etivo avaliar a eficiência do glyphosate e da mistura comercial paraquat + diuron, bem como o efeito do intervalo entre as aplicações desses herbicidas e a semeadura da soja, sobre o controle e a rebrota de Digitaria insularis, Synedrellopsis grisebachii e Leptochloa filiformis. O experimento foi conduzido em área de soja em sistema de plantio direto, utilizando-se o delineamento de blocos casualizados com nove tratamentos e quatro repetições. Foram avaliados os seguintes tratamentos: glyphosate no dia da semeadura e um, dois e cinco dias antes desta; paraquat + diuron 20 dias antes e no dia da semeadura; glyphosate 10 dias antes da semeadura e paraquat + diuron no dia da semeadura; glyphosate 15 dias antes da semeadura e paraquat + diuron no dia da semeadura; glyphosate 20 dias antes da semeadura e paraquat + diuron no dia da semeadura; e testemunha infestada. Verificou-se controle satisfatório e impedimento de rebrota de $D$. insularis e $L$. filiformis quando o glyphosate foi aplicado cinco dias antes da semeadura da soja ou quando foi realizada aplicação seqüencial de glyphosate e paraquat + diuron. Aplicações seqüenciais da mistura comercial de paraquat + diuron não foram eficientes no controle e no impedimento da rebrota de D. insularis e L. filiformis. S. grisebachii mostrou-se tolerante ao glyphosate.
\end{abstract}

Palavras-chave: Digitaria insularis, Synedrellopsis grisebachii, Leptochloa filiformis.

\begin{abstract}
The objectives of this work were to evaluate the efficiency of glyphosate and pre-formulated mixture paraquat + diuron as well as the effect of the interval between herbicide applications and soybean sowing on the control and re-growth impairment of the following weeds: Digitaria insularis, Synedrellopsis grisebach and Leptochloa filiformis. The experiment was carried out in a soybean area under no-till system and was arranged in a randomized block design, with 9 treatments and four replications. The following treatments were evaluated: glyphosate applied on sowing day; one day before sowing day; two days before sowing day; five days before sowing day; paraquat + diuron 20 days before sowing day and on sowing day; glyphosate 10 days before sowing day and paraquat + diuron on sowing day; glyphosate 15 days before sowing day and paraquat + diuron on sowing day; glyphosate 20 days before sowing day and paraquat + diuron on sowing day; and control (presence of weeds). Acceptable control and re-growth impairing of $\boldsymbol{D}$. insularis and $\boldsymbol{L}$. filiformis were obtained when glyphosate was applied five days before soybean sowing or when sequential applications of glyphosate and paraquat + diuron were applied. Sequential applications of paraquat + diuron were not efficient in controlling or impairing re-growth of the weeds $\boldsymbol{D}$. insularis and $\mathbf{L}$. filiformis. S. grisebachii showed to be tolerant to glyphosate.
\end{abstract}

Keywords: Digitaria insularis, Synedrellopsis grisebachii, Leptochloa filiformis.

Recebido para publicação em 25.8.2005 e na forma revisada em 24.2.2006.

Professor da Faculdade de Agronomia da Universidade de Rio Verde - FESURV., Caixa Postal 104, 75901-970 Rio Verde-GO, <procopio@ fesurv.br>. ${ }^{3}$ Eng.-Agr. da Cooperativa Agroindustrial dos Produtores Rurais do Sudoeste Goiano. ${ }^{4}$ Discente do curso de Agronomia da FESURV; ${ }^{5}$ Mestrando do Programa de Pós-Graduação em Produção Vegetal da FESURV. 


\section{INTRODUÇÃO}

A aplicação de herbicidas em pré-semeadura, também conhecida como dessecação de manejo, tornou-se prática obrigatória em cultivos realizados no sistema de plantio direto. Dentre os herbicidas utilizados nessa modalidade de aplicação, destacam-se o glyphosate e a mistura comercial paraquat + diuron. Aplicações em pré-semeadura de glyphosate têm apresentado bom controle de Digitaria sanguinalis, Digitaria horizontalis e Brachiaria decumbens (Barros, 2001; Jakelaitis et al., 2001; Vangessel et al., 2001a; Maciel \& Constantin, 2002). Por sua vez, Griffin et al. (2004) verificaram que a adição de diuron junto ao paraquat melhorou a eficiência de controle de Lolium multiflorum, na ordem de 11 a 17\%. Todavia, tem-se observado que o manejo químico de plantas daninhas antes da semeadura das culturas pode apresentar variações, devendo ser ajustado de acordo com as espécies de plantas daninhas presentes, o nível de infestação, as condições climáticas e edáficas e o tipo de cultura a ser semeada na área.

No intuito de elucidar a melhor seqüência de aplicação de glyphosate na cultura da soja resistente a esse herbicida, Swanton et al. (2000) observaram que, com uma primeira aplicação em pré-semeadura ou quando a soja estiver em estádio de folha unifoliolada e uma segunda aplicação quando a soja estiver com um a três trifólios, foram obtidos os melhores resultados. Vangessel et al. (2001b) constataram alta produtividade de soja resistente a glyphosate quando foi feita uma aplicação desse herbicida em pré-semeadura seguida de outra aplicação em pós-emergência, quando a cultura se encontrava entre V2 e V4. De acordo com Clayton et al. (2002), aplicações de glyphosate em estádios iniciais da cultura de canola resistente a glyphosate podem eliminar a necessidade de aplicações desse herbicida em pré-semeadura em culturas conduzidas no sistema de plantio direto. Contudo, Vangessel et al. (2001a) verificaram que a aplicação de glyphosate em pré-semeadura da soja resistente a esse herbicida não influenciou a sua eficácia quando aplicado em pós-emergência nessa cultura.

A translocação dos herbicidas é um ponto fundamental para sua eficiência em aplicações de pré-semeadura. Nessa ocasião, há predomínio de espécies perenes em estádios avançados de desenvolvimento, sendo fundamental que o herbicida atue sobre o sistema subterrâneo dessas plantas para obtenção de um controle satisfatório. Para Bromilow et al. (1990), na maioria das plantas, o glyphosate é rapidamente translocado nas folhas tratadas para os drenos metabólicos, especialmente tecidos meristemáticos e de armazenamento, sendo, por isso, excelente herbicida para o controle de plantas daninhas perenes, desde que estas estejam em plena atividade metabólica por ocasião da aplicação do herbicida. Altas intensidades luminosas nos dias subseqüentes à aplicação aumentam a velocidade de translocação do glyphosate (Schultz \& Burnside, 1980).

Este trabalho teve como objetivo avaliar a eficiência do herbicida glyphosate e da mistura comercial paraquat + diuron, aplicados em diferentes intervalos de tempo antes da semeadura da soja, sobre o controle e a rebrota de três espécies de plantas daninhas (Digitaria insularis, Synedrellopsis grisebachii e Leptochloa filiformis).

\section{MATERIAL E MÉTODOS}

O experimento foi conduzido em Rio VerdeGO, na safra 2003/2004, em área de produção de soja em sistema de plantio direto. As plantas daninhas predominantes na área experimental eram capim-amargoso (Digitaria insularis), agriãozinho (Synedrellopsis grisebachii) e capim-mimoso (Leptochloa filiformis), todas em fase reprodutiva.

O delineamento experimental utilizado foi o de blocos casualizados, sendo avaliados nove tratamentos (Tabela 1), com quatro repetições. Os herbicidas foram aplicados em présemeadura da cultura da soja, utilizando-se um pulverizador costal pressurizado com $\mathrm{CO}_{2}$, equipado com pontas de pulverização tipo leque XR110.02. O volume de calda utilizado foi de $150 \mathrm{~L} \mathrm{ha}^{-1}$.

A semeadura do cultivar Conquista no espaçamento de $0,50 \mathrm{~cm}$ foi realizada por meio de uma semeadora pneumática, regulada para liberar 18 sementes por metro. Junto à semeadura foi também realizada adubação de 
base, com $400 \mathrm{~kg} \mathrm{ha}^{-1}$ da fórmula 02-20-18. As parcelas experimentais possuíam $12 \mathrm{~m}^{2}$ (4 x $3 \mathrm{~m}$ ), sendo a área útil de avaliação de $6 \mathrm{~m}^{2}$.

Foram realizadas as seguintes avaliações: controle de plantas daninhas aos 20 dias após a semeadura (DAS), utilizando-se escala percentual de 0 a $100 \%$, os quais significam nenhum controle e morte das plantas, respectivamente; e rebrota das plantas daninhas aos 40 DAS, utilizando-se escala percentual de 0 a $100 \%$, significando nenhuma rebrota e rebrota total das plantas, respectivamente.

Após a coleta e tabulação dos dados, estes foram submetidos à análise de variância, sendo as médias das variáveis significativas comparadas pelo critério de Scott-Knott a 5\% de significância.

\section{RESULTADOS E DISCUSSÃO}

Observou-se maior eficiência no controle de Digitaria insularis quando se efetuou a aplicação do glyphosate pelo menos dois dias antes da semeadura da soja, resultado que não diferiu do controle verificado nas aplicações seqüenciais de glyphosate e paraquat + diuron (Tabela 2). O pior controle de $D$. insularis foi observado quando se realizou a aplicação seqüencial da mistura comercial de paraquat + diuron. A baixa translocação apresentada por essa mistura, associada ao fato de $D$. insularis ser planta perene e apresentar propagação vegetativa por órgãos subterrâneos, além de se encontrar em estádio avançado de desenvolvimento, são as prováveis causas da baixa eficiência constatada por esse tratamento. Quanto mais próxima a aplicação de

Tabela 1 - Tratamentos herbicidas aplicados em pré-semeadura da cultura da soja

\begin{tabular}{|l|c|}
\hline \multicolumn{1}{|c|}{ Tratamento herbicida } & Dose $\left(\mathrm{g} \mathrm{ha}^{-1}\right)$ \\
\hline Glyphosate no dia da semeadura & $1.800^{\text {e.a. }}$ \\
\hline Glyphosate 1 DAS & 1.800 \\
\hline Glyphosate 2 DAS & 1.800 \\
\hline Glyphosate 5 DAS & 1.800 \\
\hline Paraquat + diuron] 20 DAS e [paraquat + diuron] no dia da semeadura & $(300+150)^{\text {i.a. }}$ \\
\hline Glyphosate 10 DAS e [paraquat + diuron] no dia da semeadura & $1.800+(300+150)$ \\
\hline Glyphosate 15 DAS e [paraquat + diuron] no dia da semeadura & $1.800+(300+150)$ \\
\hline Glyphosate 20 DAS e [paraquat + diuron] no dia da semeadura & $1.800+(300+150)$ \\
\hline Glyphosate no dia da semeadura & - \\
\hline
\end{tabular}

Tabela 2 - Eficiência de controle de plantas daninhas aos 20 dias após a semeadura da soja, por diferentes manejos de dessecação

\begin{tabular}{|c|c|c|c|}
\hline \multirow[t]{2}{*}{ Manejo de dessecação } & $\begin{array}{l}\text { Digitaria } \\
\text { insularis }\end{array}$ & $\begin{array}{l}\text { Leptochloa } \\
\text { filiformis }\end{array}$ & $\begin{array}{c}\text { Synedrellopsis } \\
\text { grisebachii }\end{array}$ \\
\hline & \multicolumn{3}{|c|}{ Controle $(\%)$} \\
\hline Glyphosate no dia da semeadura & $63 \mathrm{c}$ & $53 \mathrm{c}$ & $0 \mathrm{c}$ \\
\hline Glyphosate $1 \mathrm{DAS}$ & $80 \mathrm{~b}$ & $81 \mathrm{~B}$ & $3 \mathrm{c}$ \\
\hline Glyphosate 2 DAS & $93 \mathrm{a}$ & $90 \mathrm{~b}$ & $43 \mathrm{~b}$ \\
\hline Glyphosate 5 DAS & 96 A & $97 \mathrm{a}$ & $10 \mathrm{c}$ \\
\hline [Paraquat + diuron] 20 DAS e [paraquat + diuron] no dia da semeadura & $50 \mathrm{~d}$ & $50 \mathrm{c}$ & $78 \mathrm{a}$ \\
\hline Glyphosate 10 DAS e [paraquat + diuron] no dia da semeadura & $99 \mathrm{a}$ & $100 \mathrm{a}$ & $88 \mathrm{a}$ \\
\hline Glyphosate 15 DAS e [paraquat + diuron] no dia da semeadura & $98 \mathrm{a}$ & $100 \mathrm{a}$ & $58 \mathrm{~b}$ \\
\hline Glyphosate 20 DAS e [paraquat + diuron] no dia da semeadura & $100 \mathrm{a}$ & $100 \mathrm{a}$ & $57 \mathrm{~b}$ \\
\hline
\end{tabular}

DAS: dias antes da semeadura. Médias seguidas de letras iguais não diferem estatisticamente pelo critério de Scott-Knott a 5\% de significância. 
glyphosate à semeadura da soja, pior foi o controle de $D$. insularis (Tabela 2). O corte das plantas promovido pelos discos da semeadora adaptada ao sistema de plantio direto, interrompendo a completa translocação do glyphosate ao sistema subterrâneo da planta, pode ser a causa da perda de eficiência dos tratamentos em que o herbicida foi aplicado apenas um dia antes da semeadura ou no mesmo dia. Li et al. (2005) relatam que mais de $65 \%$ do ${ }^{14} \mathrm{C}$-glyphosate absorvido por folhas de Amaranthus rudis foi translocado para as raízes dessas plantas, 74 horas após a aplicação do herbicida. Koger \& Reddy (2005) observaram que, do total absorvido de glyphosate por plantas de Ipomoea lacunose, 0,4 e 25,0\% tinham sido translocados da região de absorção 1 e 192 horas, respectivamente, após a aplicação. Não se detectaram diferenças na eficácia da seqüência de aplicação do glyphosate e da mistura paraquat + diuron quando seus intervalos foram de 10, 15 ou 20 dias (Tabela 2).

O melhor controle de Leptochloa filiformis foi obtido com o intervalo de cinco dias entre a aplicação de glyphosate e a semeadura da soja e com aplicações seqüenciais de glyphosate e da mistura paraquat + diuron, independentemente do intervalo da aplicação entre esses herbicidas (Tabela 2). Novamente, como observado para as plantas de $D$. insularis, as aplicações seqüenciais de paraquat + diuron não apresentaram controle satisfatório de L. filiformis, também uma gramínea perene que se encontrava em estágio avançado de desenvolvimento no início das aplicações. Werlang et al. (2002) reportam que a mistura paraquat + diuron não foi eficaz no controle de Commelina benghalensis e C. diffusa. A eficiência de controle de $L$. filiformis foi reduzindo à medida que a aplicação de glyphosate se aproximava da semeadura da soja, de forma semelhante ao observado para $D$. insularis. Todavia, o intervalo de espera necessário entre as duas operações, para L. filiformis, foi maior (cinco dias contra dois de $D$. insularis). O distanciamento da aplicação (dessecação) e da semeadura da soja proporciona fatores desfavoráveis em termos agronômicos, como maior possibilidade de emergência das plantas daninhas, junto ou mesmo anteriormente à soja; atraso na semeadura das culturas de segunda safra, como o milho, aumentando os riscos de déficit hídrico; e possibilidade de incremento de incidência de doenças da soja, como a ferrugem asiática.

Pela análise da Tabela 2, nota-se que as aplicações seqüenciais com a mistura paraquat + diuron (20 DAS e no dia da semeadura) e/ou com a seqüência de glyphosate (10 DAS) e paraquat + diuron no dia da semeadura apresentaram melhor desempenho no controle de Synedrellopsis grisebachii, espécie que se mostrou tolerante ao glyphosate. No entanto, nenhum tratamento apresentou controle dessa espécie superior a 90\% (Tabela 2). Marochi (1995) verificou que glyphosate e sulfosate mostraram-se ineficientes no controle de Richardia brasiliensis, porém, quando esses tratamentos foram complementados com a aplicação seqüencial de paraquat + diuron, o nível de controle dessa planta daninha foi superior a 96\%. Segundo Carvalho et al. (2002), o glyphosate é um dos herbicidas mais utilizados na operação de manejo; entretanto, sua alta eficiência em gramíneas não é observada no controle de algumas latifoliadas, necessitando, muitas vezes, do complemento de outros herbicidas.

A menor rebrota de $D$. insularis e $L$. filiformis foi observada nos tratamentos que receberam a aplicação em seqüência dos herbicidas glyphosate e paraquat + diuron, independentemente do intervalo entre estes, e no tratamento em que se efetuou apenas uma aplicação de glyphosate aos 5 DAS (Tabela 3). Esses resultados confirmam a importância de se observar um intervalo de pelo menos cinco dias entre a aplicação de glyphosate e a semeadura das culturas comerciais, quando há ocorrência na área de plantas de propagação vegetativa em estágio de desenvolvimento avançado. $\mathrm{O}$ maior nível de rebrota das plantas daninhas $D$. insularis e L. filiformis foi observado quando se utilizou a aplicação seqüencial da mistura paraquat + diuron, sendo em média de 83 e $75 \%$, respectivamente. A reduzida translocação dos herbicidas dessa mistura inviabiliza sua utilização isolada em áreas que apresentam infestação de gramíneas perenes, fato que pode ser revertido se posicionado de forma seqüencial, após a aplicação de glyphosate. Esses dados coincidem com os encontrados por Marochi (1995), que verificou alta porcentagem de rebrota de gramíneas com a utilização 
Tabela 3 - Rebrota de plantas daninhas aos 40 dias após a semeadura da soja, em função de diferentes manejos de dessecação

\begin{tabular}{|c|c|c|}
\hline Maneio de descecac̃̃o & Digitaria insularis & Leptochloa filiformis \\
\hline 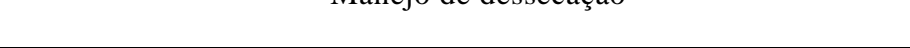 & \multicolumn{2}{|c|}{ Rebrota $(\%)$} \\
\hline Glyphosate no dia da semeadura & $23 \mathrm{~b}$ & $31 \mathrm{~b}$ \\
\hline Glyphosate 1 DAS & $21 \mathrm{~b}$ & $30 \mathrm{~b}$ \\
\hline Glyphosate 2 DAS & $23 \mathrm{~b}$ & $34 \mathrm{~b}$ \\
\hline Glyphosate 5 DAS & $3 \mathrm{c}$ & $2 \mathrm{c}$ \\
\hline [Paraquat + diuron] 20 DAS e [paraquat + diuron] no dia da semeadura & $83 \mathrm{a}$ & $75 \mathrm{a}$ \\
\hline Glyphosate 10 DAS e [paraquat + diuron] no dia da semeadura & $0 \mathrm{c}$ & $1 \mathrm{c}$ \\
\hline Glyphosate 15 DAS e [paraquat + diuron] no dia da semeadura & $5 \mathrm{c}$ & $8 \mathrm{c}$ \\
\hline Glyphosate 20 DAS e [paraquat + diuron] no dia da semeadura & $0 \mathrm{c}$ & $0 \mathrm{c}$ \\
\hline
\end{tabular}

DAS: dias antes da semeadura. Médias seguidas de letras iguais não diferem estatisticamente pelo teste de Scott-Knot a 5\% de significância.

de paraquat + diuron isoladamente ou em aplicação seqüencial, recomendando a utilização de herbicida sistêmico na primeira aplicação.

\section{LITERATURA CITADA}

BARROS, A. C. Eficiência da mistura em tanque glyphosate + carfentrazone-ethyl na dessecação de plantas daninhas.

R. Bras. Herbic., v. 2, p. 31-35, 2001.

BROMILOW, R. H.; CHAMBERLAIN, K.; EVANS, A. A. Physiochemical aspects of phloem translocation of herbicide. Weed Sci., v. 38, p. 305-314, 1990.

CARVALHO, F. T. et al. Eficácia do carfentrazone-ethyl aplicado no manejo das plantas daninhas para o plantio direto do algodão. R. Bras. Herbic., v. 3, p. 104-108, 2002.

CLAYTON, G. W. et al. Glyphosate timing and tillage system effects on glyphosate-resistant canola (Brassica napus). Weed Technol., v. 16, p. 124-130, 2002.

GRIFFIN, J. L. et al. Sugarcane tolerance and Italian ryegrass (Lolium multiflorum) control with paraquat. Weed Technol., v. 18, p. 555-559, 2004.

JAKELAITIS, A. et al. Controle de Digitaria horizontalis pelos herbicidas glyphosate, sulfosate e glyphosate potássico submetidos a diferentes intervalos de chuva após a aplicação. Planta Daninha, v. 19, p. 279-285, 2001.

KOGER, C. H.; REDDY, K. N. Glyphosate efficacy, absorption, and translocation in pitted morningglory (Ipomoea lacunosa). Weed Sci., v. 53, p. 277-283, 2005.

LI, J. et al. Influence of formulation and glyphosate salt on absorption and translocation in three annual weeds. Weed Sci., v. 53, p. 153-159, 2005.
MACIEL, C. D. G.; CONSTANTIN, J. Misturas de flumioxazin com glyphosate e sulfosate para o manejo de plantas daninhas em citros. R. Bras. Herbic., v. 3, p. 109-116, 2002.

MAROCHI, A. I. Evaluaton of chemical control methods for Richardia brasiliensis in infested areas under no-till system in the southern region of Brazil. In: ZAPP - THE CHALLENGE OF THE NEW, 1995, São Paulo. Abstracts... São Paulo: 1995. p. 57-60.

SCHULTZ, M. E.; BURNSIDE, O. C. Absorption, translocation, and metabolism of 2,4-D and glyphosate in hemp dog-bane (Apocynum cannabinum). Weed Sci., v. 27, p. 13-20, 1980.

SWANTON, C. J. et al. An economic assessment of weed control strategies in no-till glyphosate-resistant soybean (Glycine max). Weed Technol., v. 14, p. 755-763, 2000 .

VANGESSEL, M. J.; AYENI, A. O.; MAJEK, B. A. Glyphosate in double-crop no-till glyphosate-resistant soybean: role of preplant applications and residual herbicides. Weed Technol., v. 15, p. 703-713, 2001a.

VANGESSEL, M. J.; AYENI, A. O.; MAJEK, B. A. Glyphosate in full-season no-till glyphosate-resistant soybean: role of preplant applications and residual herbicides. Weed Technol., v. 15, p. 714-724, 2001b.

WERLANG, R. C.; FERREIRA, L. R.; SILVA, A. A. Efeito da aplicação seqüencial de glyphosate no controle de Commelina benghalensis e Commelina diffusa na cultura do cafeeiro. R. Bras. Herbic., v. 3, p. 33-38, 2002.

Planta Daninha, Viçosa-MG, v. 24, n. 1, p. 193-197, 2006 